\title{
COMPETITIVIDAD EN EL SECTOR GANADERO EN COLOMBIA ENFOQUE DESDE LA HISTORIOGRAFÍA ECONÓMICA, SOCIAL Y EMPRESARIAL
}

Aylin Patricia Pertuz Martínez

Universidad de Sucre Colombia

Jorge Enrique Elías Caro Universidad del Magdalena Colombia 


\title{
Competitividad en el sector ganadero en Colombia: Enfoque desde la historiografía económica, social y empresarial
}

\section{Resumen}

Este trabajo tiene como objetivo caracterizar al sector ganadero colombiano y sus organizaciones en términos de su competitividad, con base en la historiografía económica, social y empresarial que se ha escrito sobre esta problemática, en especial para los siglos XIX-XX. En este trabajo se concluye que las organizaciones y el sector ganadero colombiano no han sido competitivos, lo cual se muestra en los bajos niveles de productividad y calidad de sus productos en comparación con otros países. Factores externos y endógenos estructurales no han permitido el desarrollo del sector, estando entre ellos el sistema de producción extensiva que aún sigue siendo el preponderante del siglo XXI.

Palabras clave: Colombia, ganadería, competitividad, productividad, calidad.

\section{Compétitivité dans le secteur de l'élevage en Colombie: approche de l'historiographie économique, sociale et commerciale}

\section{Résumé}

Ce travail vise à caractériser le secteur de l'élevage colombien et ses organisations en termes de compétitivité, sur la base de l'historiographie économique, sociale et commerciale qui a écrit sur cette question, pour les XIXe et XXe siècles. Il est conclu que les organisations et le secteur de l'élevage colombien n'ont pas été compétitifs, comme en témoignent les faibles niveaux de productivité et de qualité de leurs produits par rapport à d'autres pays. Les facteurs structurels externes et endogènes n'ont pas permis le développement du secteur, étant parmi eux le système de production extensif continue d'être la prédominance du XXIe siècle.

Mots clés: Colombie, élevage, compétitivité, productivité, qualité.

\section{Competitiveness in the livestock sector in Colombia: Approach from economic, social and business historiography}

\begin{abstract}
This work aims to characterize the Colombian livestock sector and its organizations in terms of their competitiveness, based on the economic, social and business historiography that wrote about this issue, for the 19th-20th centuries. It is concluded that the organizations and the Colombian livestock sector have not been competitive, which is evidenced in the low levels of productivity and quality of their products compared to other countries. External and endogenous structural factors have not allowed the development of the sector, being among them the extensive production system continues to be the predominance of the 21st century.
\end{abstract}

Keywords: Colombia, livestock, competitiveness, productivity, quality. 


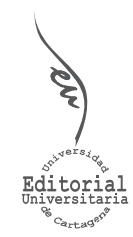

Artículo de Investigación

\section{Competitividad en el sector ganadero en Colombia: Enfoque desde la historiografía económica, social y empresarial}

INFORMACIÓN DEL ARTíCULO

Recepción del artículo: 05/01/2019

Concepto de evaluación: 15/02/2019

Aceptación del artículo: 21/03/2019
Aylin Patricia Pertuz Martínez

Universidad de Sucre, Colombia

Jorge Enrique Elías Caro Universidad del Magdalena, Colombia

\section{INTRODUCCIÓN}

La competitividad no es un objetivo a alcanzar, sino un proceso continuo de esfuerzos entre todos hacia la obtención de atributos diferenciados, siendo los resultados de largo plazo. Los factores de competitividad que son modificables por las estrategias de la empresa se denominan "endógenos". La productividad puede incrementarse por la estrategia productiva; cambios en la política de recursos humanos; o se podrían utilizar estrategias con "base en el poder de mercado"; mejor gestión financiera; entre otros (Horta y Jung, 2002). La competitividad de las empresas, también depende de dos factores "exógenos" a las decisiones: los "factores sistémicos", es decir, al entorno general con sus componentes de contexto macroeconómico e internacional y de políticas públicas; y de los denominados "factores estructurales o sectoriales", relacionados con la estructura de los mercados en los que opera la empresa y en los que influye sólo de forma parcial, lo cual incluye los otros tres elementos del diamante de Porter (Ubfal, 2004).

En cuanto a la productividad, la cual es considerada un sinónimo de eficiencia, eficacia o efectividad organizacional, Carro y González (2012), la definen como la comparación positiva entre los recursos utilizados y la cantidad de bienes/servicios producidos. La calidad es un asunto cualitativo y subjetivo. Puede aplicarse a la producción, a los productos o al valor del producto. Aplicada al producto hace referencia a una serie de "atributos deseables". En las normas ISO 9000, la calidad se define como la facultad de un conjunto de características que son propias de un producto, sistema o proceso para 
cumplir con los requerimientos de los clientes u otros (Griful y Canela, 2005). La calidad y la productividad son elementos de la competitividad.

Como bases legales de apoyo al sector ganadero se encuentran las leyes: 41 de 1993; 89 de 1993, que establece la cuota de Fomento Ganadero y Lechero y se crea el Fondo Nacional del Ganado; 101 de 1993; 395 de 1997, por la que se declara como prioridad sanitaria la erradicación de la fiebre aftosa; 914 de 2004 que crea el Sistema Nacional de Identificación e Información del Ganado Bovino; así como otros decretos y documentos CONPES, como los 3376 y 3676, para consolidar la política sanitaria e inocuidad de las cadenas láctea y cárnica.

A partir de lo anterior, con este trabajo se caracteriza al sector ganadero colombiano y sus organizaciones en términos de su competitividad, con base en lo registrado en la historiografía económica, social y empresarial.

\section{COMPETITIVIDAD EN EL SECTOR GANADERO EN COLOMBIA}

\subsection{Balance historiográfico}

Este trabajo es el producto de la revisión historiográfica de 91 textos. Las publicaciones comprenden desde la década de 1920 hasta los inicios del siglo XXI. En las primeras décadas del siglo XX, e incluso finalizando este siglo, la producción no es abundante, aspecto que cambia en los primeros años del siglo XXI. El 36,2\% de los textos corresponde a informes y documentos de trabajos. En algunas variables los datos son parecidos, pero en otros son diferentes, debido a los inconvenientes para la obtención de información del sector ganadero, en casi todo el siglo XX (ver cuadro 1).

Cuadro 1.

Balance historiográfico.

$\begin{array}{ll}\text { Libros: } & 23\end{array}$

Artículos: $\quad 23$

Trabajos de pregrado: $\quad 3$

Trabajos de posgrado: $\quad 7$

Capítulos de libro: $\quad 2$

Informes de investigación y documentos de trabajo: 33

Total textos:

91

Fuente: Elaboración propia

\subsection{Siglo XIX hasta los primeros años del siglo $\mathrm{XXI}$}

\subsubsection{Aspectos generales}

Con base en distintos estudios en Colombia, en 1938 se contaba con 8.1 millones de cabezas de ganado; en 1950 subió a 15.5 millones; en 1954 fue de 10.0 millones y en 1964 fue de 14.1 millones, para un crecimiento de 2,5\%, según el Departamento Administrativo Nacional de Estadística (DANE). Ello quiere decir, que el hato ganadero creció en los años 
cuarenta, se estancó a inicios de los años cincuenta, creció entre 1955 a 1965, y al final de los sesenta tuvo un crecimiento acelerado. De 1950 a 1975, la tasa de crecimiento fue de 2,5\% (Hertford y Nores, 1982). En la mitad de los noventa, existían aproximadamente 23 millones de cabezas de ganado (Pérez, 2004), cifra que se conserva para 2013, según Espinosa (2014).

La ganadería bovina contribuye con el 1,6\% del PIB de Colombia y es un 53\% del PIB pecuario (FEDEGÁN, 2012, citado en Espinosa, 2014). Según Santana (2014), el valor de la producción de carne y subproductos era de $\$ 5.602,5$ miles de millones de pesos. La producción de leche de doble propósito fue de 3.639 millones lts/año. La lechería especializada fue de 2.977 millones lts/año. El acopio industrial estuvo en 2.930 millones lts/año.

\subsubsection{Factores positivos en la ganadería colombiana. Siglo XIX-Década de 1950}

El ganado en Colombia llegó con la conquista española. Trescientos años después del proceso de la colonización comenzaron a presentarse cambios lentos y pequeños, en términos técnicos, pero significativos. Los cambios generados en los siglos XIX y primeros cincuenta años del siglo XX, se muestran en las figuras 1 y 2, con base en los autores: Posada (2003), Bossa (1967), Oakley, citado en Posada (2006), Van Ausdal (2009), Burgos (2000), Fals (1987), Reyes (1978), García (2003, citado en Arias, 2004), Ocampo (2007), Brew (2000), Bell (1921), Bejarano (1987), Sourdís, (2008), Álvarez (2012), Pertuz (2008), Negrete (2009), Ripoll (1997), Viloria (2001), Parsons (1992, citado en Viloria, 2004), Machado (1989).

Figura 1. Factores para el mejoramiento de la competitividad, 1840-1920.

\begin{tabular}{|c|c|}
\hline $1840-1990$ & $\begin{array}{l}\text { - Pastos naturales en Bolívar } \\
\text { - Los ríos producían aluviones para el pastoreo en el Sinú } \\
\text { - Introducción de la yerba pará } \\
\text { - Introducción de razas } \\
\text { - Exportaciones de ganado en pie a Cuba } \\
\text { - Introducción del alambre de púas } \\
\text { - El ganado podía transportarse a pie } \\
\text { - Ganado resistente a enfermedades }\end{array}$ \\
\hline $1900-1920$ & $\begin{array}{l}\text { - Costa Caribe: producción de carne } \\
\text { - Bogotá y Antioquia: producción de leche } \\
\text { - Exportaciones de ganado en pie } \\
\text { - Salinidad del aire: animales sanos en Costa Caribe } \\
\text { - Animales resistentes a enfermedades } \\
\text { - Cruces de ganado } \\
\text { - Buenas pasturas en el interior del país } \\
\text { - Importación de razas en el interior del país } \\
\text { - Comercio ganadero masivo en Antioquia } \\
\text { Factores externos } \\
\text { - Construcción de vías de comunicación hacia el interior } \\
\text { - Concesiones de tierras públicas } \\
\text { - Uso de transporte fluvial hacia el interior } \\
\text { - Ampliación del mercado interno }\end{array}$ \\
\hline
\end{tabular}

Fuente: Elaboración propia con base en la historiografía señalada 
La presencia de pastos naturales en el Caribe no se dio naturalmente como en La Pampa argentina, sino que fue producto de la tala y quema de bosques. Posada (2003), también expresa que no se presentaron grandes hatos a diferencia de otras regiones del hemisferio. Van Ausdal (2009), resalta el tiempo, esfuerzo y costos para convertir el bosque en sabana.

Una ventaja para el ganadero era que el ganado podía transportase en pie. Posada (2003), señala que en Colombia no existía un medio de transporte moderno, y el ferrocarril no fue una opción por la topografía del terreno. Para transportar las reses de una región a otra, los ganaderos de las sabanas de Bolívar abrieron trochas o caminos de herradura, que cubrían grandes distancias. Según Meisel y Viloria (1999), Adolfo Held, hacia los años treinta, enviaba el ganado de primera a la Feria de Medellín; el ganado de segunda a Manizales y algo para Bogotá y Cali; el ganado de inferior calidad (vacas viejas y toros capados en su consideración), los enviaba a Bucaramanga. La yerba pará, las nuevas razas de ganado y el alambre de púas, llegaron al país en la segunda mitad del siglo XIX y principios del siglo $\mathrm{XX}$, siendo importados por ganaderos que tuvieron contacto con estas innovaciones en otros países. La introducción del alambre de púas se introdujo en las sabanas de Bolívar después de 1850, pero no fue extendido debido al costo de esta implementación; según Reyes (1978), sólo los latifundistas podían hacer estas inversiones, y, de acuerdo con Fals (1987), fue utilizado por estos, para apropiarse de tierras comunales y playones.

Las nuevas razas, no obedecieron tampoco a políticas gubernamentales, a planes o decisiones concertadas entre los ganaderos, sino a iniciativas particulares. No siempre la introducción de una nueva raza para su explotación o para cruces con ganado nativo era exitosa, dado que para la época no existían los conocimientos necesarios, y los desarrollos fueron dándose bajo prueba y error o en forma empírica. A pesar de ello, se fueron presentando avances. Gallini (2005), indica que a principios de siglo XX empezaron a conformarse las asociaciones de criadores que crearon monopolios de razas puras y las ferias ganaderas. La introducción de las innovaciones respondió a una ampliación del mercado. Reyes (1978), muestra que la importación de nuevas razas, como las realizadas por Adolfo Held, respondió a esta oportunidad. En el país, las razas criollas eran la mayoría.

La introducción del ganado cebú tuvo varios propósitos a inicios del siglo XX. De acuerdo con Pérez (2015), en el Ingenio Manuelita, fue utilizado como animal de tiro y arrastre; Adolfo Held, lo usó para mejorar el ganado criollo y en los santanderes, su masificación y mezcla con el ganado nativo hizo desaparecer las razas criollas. La incorporación de nuevas razas de ganado en el país no fue un asunto generalizado, tanto así, que Flórez (2008), expresa que el listado de criadores no era extenso. Según Bell (1921), Bogotá fue la única región donde se estimuló la mejora de razas en el país, siendo resistentes a enfermedades y garrapatas. Mejía (2003), a diferencia de Bell, manifiesta que, a pesar de ser el Valle del Cauca, una región atrasada en lo agropecuario referente a otras zonas del país a principios del siglo XX, el hacendado Ciro Molina realizó importaciones de toros reproductores durham y holstein.

Respecto a las exportaciones, fueron producto de oportunidades (guerras civiles, de independencia o mundiales) en mercados cercanos. Estas se dirigieron a Cuba, Panamá y en menor proporción a México y Venezuela. De acuerdo con Meisel (2009), estas exportaciones no fueron significativas entre 1905 a 1950, a excepción de coyunturas del entorno, como la construcción del canal de Panamá y la Primera Guerra Mundial.

Dentro de los factores externos de la competitividad, como expresa Ubfal (2004), en 
la primera mitad del siglo XX, la ganadería se expandió por las concesiones de tierras públicas; es así como Bejarano (1987), indica que, de las 923.743 hectáreas de baldíos concedidas en el territorio colombiano entre 1910 a 1937, el 29,6\% fueron adjudicados en el antiguo Bolívar. Van Ausdal (2009), por su parte, explica que el Estado necesitaba recursos y utilizó las tierras baldías para obtenerlos. Otro factor fue la ampliación del mercado interno debido a la producción del café y la integración de las regiones del país, según manifiesta Kalmanovitz y Enciso (2005).

Figura 2. Factores para el mejoramiento de la competitividad, 1921-1950.

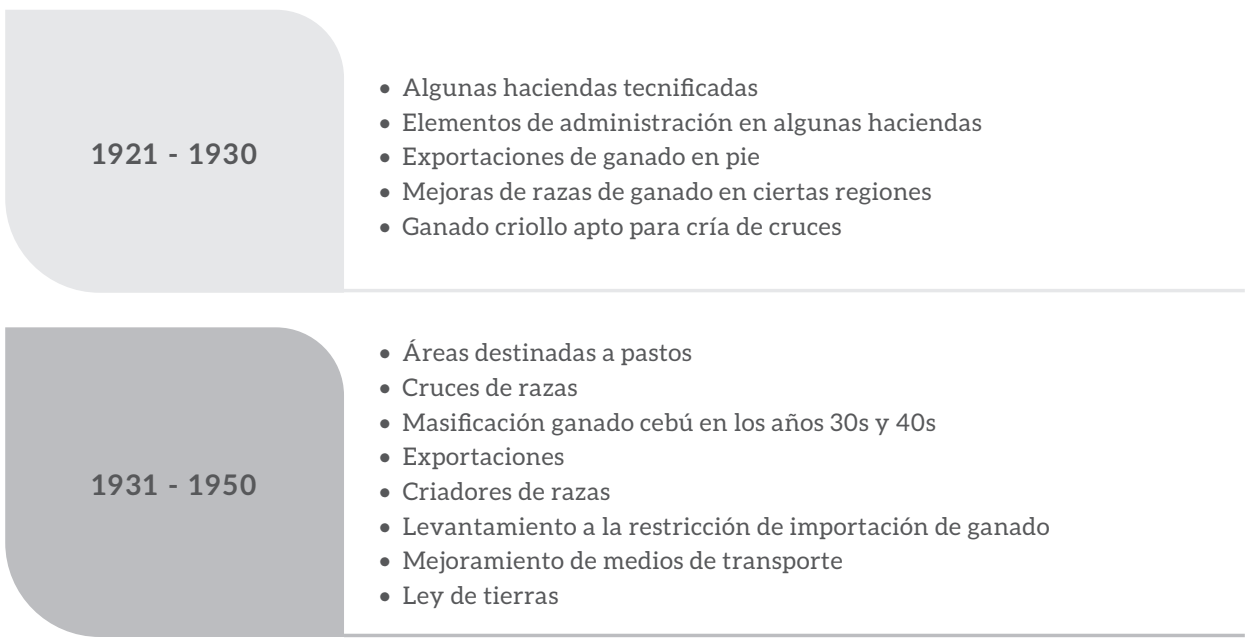

Fuente: : Elaboración propia con base en la historiografía señalada

Del año 1921 a 1950 se presentó una leve mejoría en ciertos factores internos de la competitividad como la presencia de algunas haciendas organizadas, tal como registra Ocampo (2007), con la hacienda Marta Magdalena, aunque ésta no era la generalidad en el país. Elementos externos que favorecieron al sector, lo muestra Pérez (2015), con la eliminación en 1939 de la restricción a la importación de ganado cebú que se había dado en 1931. La Ley de Tierras a finales de los años treinta, favoreció también al "latifundio ganadero".

\subsubsection{Limitantes para la ganadería. Siglo XIX hasta la década de 1970.}

La falta de competitividad y productividad de la ganadería a finales del siglo XIX y primeros cincuenta años del siglo XX estuvo relacionada principalmente con la utilización del sistema de pastoreo extensivo, pero, de acuerdo con los autores Posada, Meisel, Van Ausdal y Viloria, este sistema fue la adaptación de los ganaderos al contexto externo, dadas sus limitaciones, a diferencia de los autores Reyes o Fals, que tienden a colocar la racionalidad del ganadero en términos de poder, prestigio social y control político. Para Legrand (1988), los ganaderos querían tanto dinero como prestigio social.

Las difusiones tecnológicas no fueron procesos masivos ni sistematizados o tecnificados. No existían estadísticas de los procesos de selección de razas. El pasto mayormente 
utilizado no era de buena calidad, lo que unido a un ganado criollo de poco engorde daba una carne de mala calidad. Respecto a los suelos, en general tenían un pobre contenido de cal y minerales; como indica Gallini (2005), las composiciones químicas de los suelos hacían más difícil la implantación de los pastos artificiales, y aunque los suelos en tierras altas eran mejores, estaban sometidos al verano. El ganadero debía trasladar su ganado a tierras bajas para alimentarlo (trashumancia).

En los años veinte, en la costa Caribe se intentó exportar carne refrigerada a países europeos y Estados Unidos, a través del Packing House de Coveñas, pero el precio fue considerado alto en comparación de la carne que fue vista de segunda. Muy diferente fue Argentina, en donde, según Reyes (2015), las exportaciones de carne refrigerada crecieron exponencialmente a principios del siglo XX, y los frigoríficos impulsaron encadenamientos de demanda y oferta. Argentina alcanzó el mercado británico luego de un largo camino en el que se cruzaron razas, se mejoró la alimentación, se usaron las tierras para la cría y el engorde de los animales en combinación con nuevos productos agrícolas.

En los años treinta del siglo XX, Velázquez (1938), exponía que no era posible competirle a Argentina en el mercado de la carne, por el alto precio del producto. Esto tenía como causas el problema de los forrajes, puesto que en Argentina se utilizaba la alfalfa, en cambio en Colombia con la yerba pará, guinea, india, yaraguá, uribe, el novillo necesitaba ocho meses para estar gordo. Con la alfalfa se cebaba en cuatro meses o un poco más; la selección y el cruzamiento, puesto que la selección era más segura pero más lenta, y el cruce de razas era más rápido, pero más proclive a los fracasos porque el animal entraba en una lucha para adaptarse al nuevo entorno donde podía morir o degenerarse por las enfermedades; el precio de la sal o los impuestos dirigidos al sector.

La cadena productiva presentó una gran cantidad de intermediarios entre el productor y el consumidor final, los cuales iban conectando las distintas fases de la producción primaria -cría, levante, ceba-. La extensa cadena estaba relacionada con las inversiones de capital de los ganaderos que no eran suficientes para cubrir gran parte de la misma. De acuerdo con Posada (2006), el ganado podía pasar por seis o siete personas antes de llegar al minorista: de criador a un comprador, y posiblemente a otro comprador, luego a levante, a embarque, después al cebador, para llegar al carnicero.

El transporte del ganado en pie seguía generando pérdidas de peso de los animales, más los heridos o fallecidos. Brew (2000), anota que en los años 20 se utilizaba un ferrocarril, para disminuirlas. Las pérdidas por peso eran en los años cincuenta para el ganado cordobés con destino a Medellín de unos $100 \mathrm{~kg}$ por cabeza en 45 días de viaje, según el Departamento de Investigaciones Económicas de la Caja de Crédito Agrario (1961). Para tratar de disminuir esta situación los ganaderos hacían pastar sus reses en haciendas para terminar de cebarlas cerca del lugar de destino.

Los aspectos organizativos-administrativos, no eran problemas complementarios, sino que hacían partedel círculo de limitantes en una relación causa-efecto. La desorganización administrativa, la despreocupación por el manejo de los animales, el ausentismo de los ganaderos, fueron características recurrentes. Para el ganadero no había motivos para invertir ya que el mercado no correspondería con el precio, teniendo en cuenta que existía una población con bajos ingresos y costumbres alimenticias arraigadas. El ausentismo era una forma de disminución de costos en un sistema extensivo.

Dentro de los factores externos, estuvo la prohibición de las exportaciones al exterior, puesto que al interior del país se consideraba que las exportaciones desabastecerían el mercado local, idea impulsada por las asociaciones de ganaderos de esa región. 
Figura 3. Causas de la baja competitividad. Finales siglo XIX - Años 1970s.

\section{Factores internos y de la cadena productiva}

Sistema de producción extensivo en carne y leche

Producción de leche arcaica finales siglo XIX

Baja población en animales, bajo peso y alta mortalidad

Pastos sin calidad y enmalezamiento de los potreros

Cruces de razas inadecuados

Carne de mala calidad

Costo de las enfermedades

Carne costosa por la ceba, superior a otros países

Poca capacidad de engorde del ganado criollo

Suelos de pobre contenido en sal y minerales

No masificación del alambre de púas

Muy lenta introducción de la yerba pará

Lenta incorporación de nuevas razas

Costo del transporte

Comercialización de la leche sin condiciones sanitarias (60s)

Precio de la sal

Ganado sin higiene

Presencia de garrapatas y enfermedades

Pérdida de peso de los animales por viajes

Costos de las Técnicas

Ciclo ganadero extendido

Trashumancia en varias zonas

Mataderos en mal estado. Sin cumplimiento de normas

Falta de industria frigorífica moderna

Falta de integración

Despreocupación en el manejo de los animales

Desorganización administrativa

Altibajos en los precios

Lácteo: control del mercado por los intermediarios

Poco control de inversiones y costos

\section{Factores externos y de la cadena productiva}

Algunas regiones sin acceso a mercados

Malas vías de comunicación

Período de prohibición para la importación del ganado cebú

Presión sobre los gobiernos para evitar exportaciones Escaso apoyo del Estado

Falta de crédito en buenas condiciones

Mercado estrecho

Productos sustitutos como el pollo

Demanda de la carne, elasticidad-precio y elasticidad-ingreso

Apreciación del peso colombiano en algunos periodos Impuestos

Fuente: Elaboración propia con base en: Bolívar (2008), Bell (1921), Ocampo (2007), Machado (1989), Pertuz (2008), Currie (1962), Departamento de Investigaciones Económicas de la Caja de Crédito Agrario (1961), Federación Antioqueña de Ganaderos (1980), López (1927), Posada (1994), Rivas y Cordeu (1983), Cuenca, Chavarro y Díaz (2008), Meisel (1999, citado en Ripoll,1999), Uribe (2011), Kalmanovitz y Enciso (2005), Cruz, Peñuela, Gómez y Cedeño (1972). 


\subsubsection{Avances de la ganadería colombiana. Décadas de 1950-2010.}

Después de 1950 los avances en la ganadería se presentan en las figuras 4 y 5, con base en los autores: Hertfort y Nores (1982), Aldana (1993, citado en Jaramillo y Caicedo, 1996), Bonet (1998), Pérez (2015), Gil (2008), Martínez (2011), Bowser (1969), (Barrera, 2010), Londoño (2013), Rivas (1981), Departamento Nacional de Planeación (1980), Medina, Sejín, Saa, Bustamante y Ochoa (1984), Agrocadenas (2006).

Figura 4. Factores para el mejoramiento de la competitividad, 1950-1990.
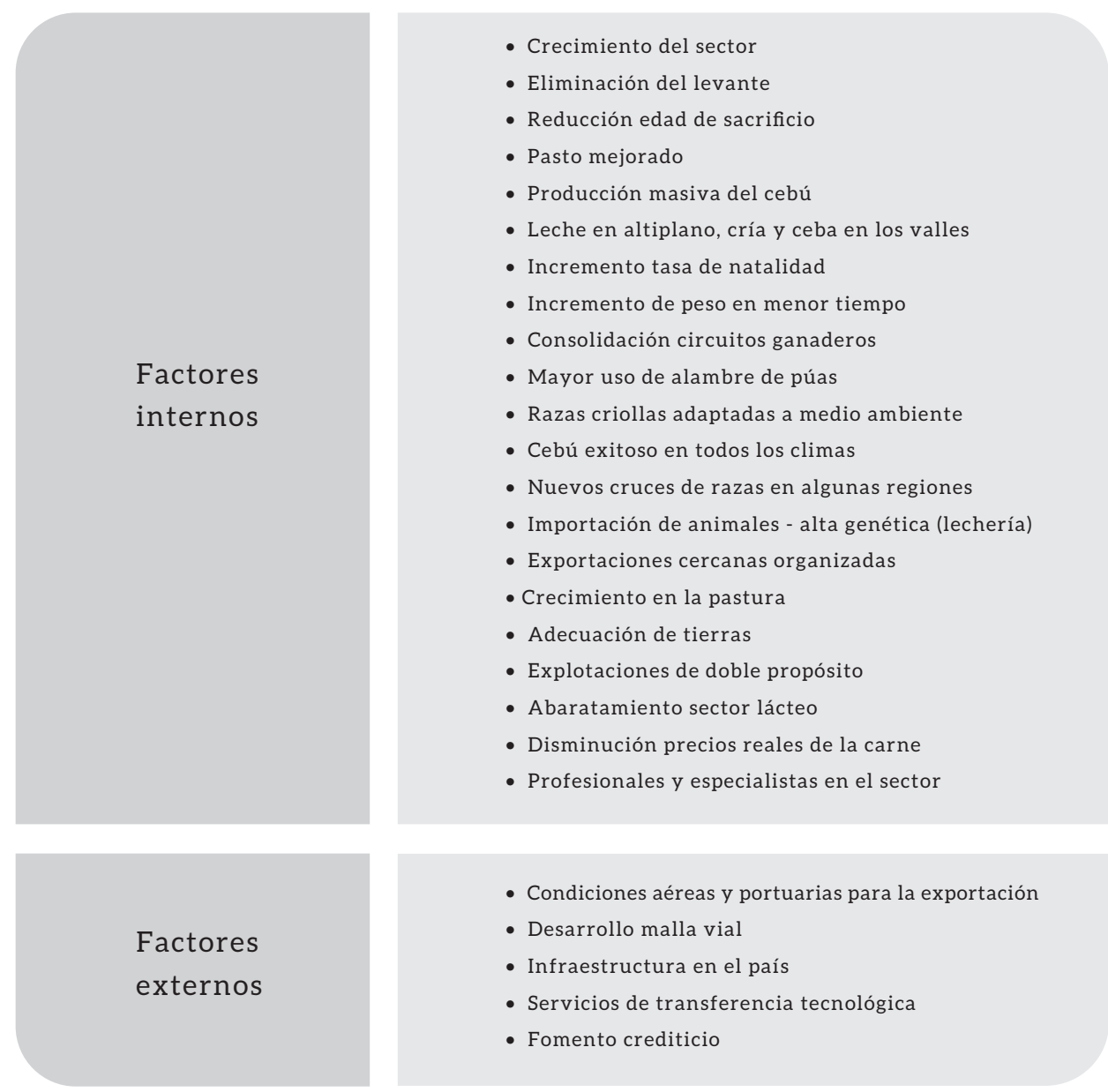

- Condiciones aéreas y portuarias para la exportación

- Desarrollo malla vial

- Infraestructura en el país

- Servicios de transferencia tecnológica

- Fomento crediticio

Fuente: Elaboración propia con base en los autores señalados

El ciclo ganadero en Colombia era de seis a ocho años entre los años 1950s a 1970s, según demuestran los estudios. La producción ganadera era estacional, puesto que la sequía y el invierno afectaban la calidad de los pastos, el peso de las reses y el volumen de sacrificio. De 1952 a 1973, según Llorente (1986), se dio un cambio tecnológico muy importante: la 
desaparición lenta del periodo de levante, junto con la aplicación del pasto mejorado, proceso que para 1972 tuvo la intervención favorable del INCORA.

La disminución del levante y la utilización de mejores pastos facilitó la disminución de la edad de sacrificio de los animales, que según Aldana (1993, citado en Jaramillo y Caicedo, 1996) pasó de 57 meses a 35 meses en el período de 1958 a 1993, y así mismo, se aumentó la tasa de natalidad de 1956 a los años setenta, se estancó en parte de los años ochenta, volvió a crecer y se estabilizó hacia 1993. Pérez (2004), muestra un ciclo de cuatro años entre 1981 a 1985 y otro de cinco años entre 1985 a 1990. La pastura se expandió según Arias (1992), entre 1950 a 1978, teniendo como causas la colonización y la expansión de la agricultura. El aumento de la producción de ganado se debió al incremento de la pastura en un 69,4\% y el resto en productividad. Para la década del cincuenta, una res de 5.5 a 6 años obtenía 400 a 500 kg, y en 1980, una res de 3.5 a 5 años conseguía 400 kg.

La estrategia del doble propósito, según Arias (1992), se extendió debido a factores externos expuestos en la figura 4. En los ochenta, existían diversos sistemas productivos con una clara diferenciación tecnológica; el pastoreo intensivo de alta productividad correspondía a la lechería especializada, doble propósito y ceba. La producción de carne se hacía en el sistema de pastoreo intensivo suplementado.

A finales del siglo XX, mejoró la calidad de la carne (mayor pulpa sin tanto hueso), y se elevó la producción de carnes procesadas, aspecto significativo, teniendo en cuenta que en Colombia se ha dado la costumbre del consumo de carne "fresca". La calidad de la leche mejoró en los años setenta y ochenta. La capacidad instalada se dio cerca de los centros urbanos, pero la pulverización se dio en las áreas rurales. Según Vargas (1987), esto permitía abaratamiento de costos incluyendo servicios públicos. De acuerdo con Gómez (1976), ya existían empresas privadas y cooperativas procesadoras de leche con avances en acopio y transporte en frío.

Respecto a la integración del sector, para autores como Vargas (1987) el mercado de carne estaba bien integrado en los últimos años del siglo XX, con relación a los precios; para otros como Llorente (1986), tanto el mercado de carne como el lácteo no estaba bien integrado entre la red de comercialización y el productor, pero el sector cárnico estaba mejor integrado que el lácteo debido a que la producción "no estuvo organizada en función de la demanda local" y el ganado podía transportarse.

En esta cadena productiva, los frigoríficos conectaron a los productores con los consumidores, aunque en los noventa tuvieron sus altibajos. Estos frigoríficos empezaron a comercializar carne madurada, despostada y empacada al vacío. La Feria de Ganados de Medellín seguía estando posicionada, según Bonet (1998), fijando precios para el ganado extra, primera, segunda y tercera para machos y hembras. Pero en el Caribe, surgieron las subastas generando un nuevo tipo de mercado. Con el tiempo la feria de Medellín perderá su preponderancia. En la comercialización entraron grandes almacenes de cadena para la venta de carne madurada, despostada y empacada al vacío, estableciéndose según FEDEGÁN (2000), un nuevo segmento de mercado.

Un factor externo que permitió una mejor integración del sector ganadero fue el desarrollo de la malla vial. Bonet (1998), señala la consolidación de dos circuitos ganaderos: el circuito entre el Cesar, sur de la Guajira, y el Magdalena con Barranquilla, Norte de Santander, Santander, el Magdalena Medio y Bogotá; y el circuito que comunicó a Antioquia, Córdoba, Sucre y Bolívar, para atender además el Valle del Cauca y la zona 
cafetera. Significativa fue la titularización del ganado como herramienta financiera para dinamizar el sector a través de la Bolsa Nacional Agropecuaria. De 1995 a 2001 el área sembrada de pastos creció en tres millones de hectáreas, es decir, un crecimiento del $2 \%$ en promedio anual, según Viloria (2005), pero se ha dado una escasez de pasto mejorado, indispensable para elevar la productividad.

Según Londoño (2013), en la Feria de Medellín, se vende el "novillo gordo en pie", dirigido a los exportadores de ganado en pie, y los comercializadores de carne en canal y carne empacada al vacío. Las empresas que producen en grandes volúmenes, tienen menor costo de producción y mayor poder de negociación ante proveedores, por lo tanto, las empresas que entran nuevas deben trabajar a gran escala para no estar en desventaja. Los vendedores de ganado flaco, venden ganado diferenciado porque venden machos de levante y machos de ceba con diversos atributos como "edad, raza, nivel de cruzamiento, peso, calidad y color". Este aspecto, es congruente con lo expresado por Porter, respecto a las fuerzas competitivas de la industria.

Figura 5. Factores para el mejoramiento de la competitividad de la ganadería colombiana 1990-2010.

\section{0-2010.}

- Mejor integración del sector

- Abaratamiento sector lácteo

- Incremento carnes procesadas

- Creación de frigoríficos

- Creación y consolidación de subastas

- Titularización del ganado

- Cadenas de almacenes en la comercialización

- Abastecimiento mercado interno

- Aumento producción de leche

- Crecimiento área de pastos

- Especies forrajeras

- Luminosidad todo el año

- Cruces genéticos adecuados al ambiente

- Razas puras mejoradas

- Mejoramiento de ganado criollo

- Ganado propicio para el doble propósito

- Mano de obra barata

- Integración vertical hacia delante en la cadena cárnica

- Carne libre de aftosa con vacunación

- En algunas regiones no se utilizan hormonas para el ganado de carne

- Ubicación geográfica del país

- Posibilidades para la carne natural u orgánica

- Lácteo: inversión en potreros

- Lácteo: reducción de costos unitarios de producción

- Industria procesadora, leche pasteurizada

Fuente: Elaboración propia con base en los autores señalados. 
Las subastas se han consolidado, en especial, porque según Martínez (2011) disminuyen costos de transacción, evitando posibles fraudes en las transacciones; es decir, son transparentes para colocar precios, según el Ministerio de Agricultura y Desarrollo Rural (2003).

En cuanto a la calidad, en el sector cárnico, Colombia tiene como fortalezas, de acuerdo con López, Andrade, Muñoz y Pulido (2012), la presencia de carne de calidad libre de EEB (Encefalopatía espongiforme bovina); es libre de aftosa con vacunación; se ha puesto en marcha un sistema de trazabilidad (SINIGAN); y, en algunas regiones se utilizan hormonas en la producción.

La producción del sector lácteo, según Barrios y Olivera (2013) es actualmente de un $4 \%$ en lechería especializada y un $60 \%$ de doble propósito. En su estudio, el margen de utilidad/litro leche fue del 20,8\%; la tasa interna de retorno fue de 27,3\%; el costo de la alimentación fue de $52 \%$, la mano de obra, 19,4\%, y sanidad 8,4\%. Los municipios de Antioquia con mayor producción generan menores costos debido a las economías de escala; aspecto también mencionado por Porter, en las fuerzas de la industria. La reducción de los costos unitarios de producción, por mejores pasturas e inversión en potreros para rotar las pasturas, ha mejorado la competitividad (Hollman et al, 2004).

Los acuerdos de competitividad para la cadena láctea en diferentes años han sido importantes para el sector, pero desafortunadamente, según Quintero (2011), no se han concretado los proyectos a implementar. Es decir, con la ayuda de los gremios, se han articulado políticas para el sector, a diferencia de lo acontecido en los primeros cincuenta años del siglo XX, pero sigue persistiendo en el país, la falta de implementación de las políticas y su sostenimiento.

Un avance importante, ha sido la implementación de la inseminación artificial para el mejoramiento genético. Giraldo (2007), plantea que la inseminación es común y se está haciendo con el respaldo de estudios, pero el país difiere del origen, respecto a su nutrición; clima; manejo de los ganados; tipo de alojamiento de los animales (pastoreo o confinamiento); y, el tipo de explotación. La cadena láctea que había tenido grandes problemas en el siglo XX, se trasformó en los primeros años del siglo XXI, especialmente en la parte industrial de esta cadena, en la cual se evidencian las mejoras tecnológicas.

\subsubsection{Factores limitantes. 1990-2010.}

Llegado el siglo XXI, el sector ganadero colombiano sigue estando por debajo de los estándares internacionales, como puede verse en los cuadros 2 y 3 . Los factores que han imposibilitado el poder competir en condiciones similares a otros países no han cambiado mucho en el transcurso de las décadas. Los avances no han sido suficientes porque los cambios e innovaciones no han sido implementados en forma sistematizada o generalizada, además, la evolución del mercado internacional presenta mayores exigencias.

El sistema extensivo predomina. Según Viloria (2005), este sistema está unido a los problemas de tasas de natalidad, pastos inapropiados, tecnología atrasada, manejo gerencial deficiente, factores que generan una baja productividad y una calidad del producto no conforme o por debajo de los estándares internacionales. Igualmente, la falta de asociatividad empresarial en el eslabón primario, la alta informalidad, la falta 
de higiene y procesos alimenticios de calidad y salubridad en los mataderos o el manejo inadecuado de la carne en los canales de conservación o distribución.

Es de aclarar, que la tecnología tradicional del sistema extensivo, es aquella que hace uso de pastos naturales, suministro de sal inferior a los estándares, falta de la rotación de potreros, y no hay selección del ganado. Rivas (1981), agrega que la "tecnología mejorada", implica el uso de pastos mejorados, suministro de sal de $22 \mathrm{~kg} / \mathrm{año} / \mathrm{UA}$ aproximadamente, hay rotación de potreros y selección de vacunos. Falta una óptima integración en estos últimos años, a pesar de la instalación de frigoríficos, en el caso del sector cárnico, para disminuir la cantidad de intermediarios, pero dichos frigoríficos, como establece Guarín (2008), han sido un espacio para que actúe el intermediario; tampoco están en la vanguardia tecnológica.

Especial atención merecen los costos de producción y el precio de los productos. Hay regiones en el país que en las últimas décadas del siglo XX no realizaron inversiones por los costos de las mismas. Muchos ganaderos se han visto en la disyuntiva de incrementar los costos al contar con nuevas tecnologías y esperar tener productividad-ingresos, o continuar con un sistema tradicional que disminuye costos. Empero, si se diera un sistema sin uso de concentrados, fertilizantes, plaguicidas y químicos, según Gil (2008), los costos importados serían menos del 10\%, escenario que por sí solo haría "inviable" la ganadería del país.

Las cifras no distan de los datos de la década de los ochenta, en donde, según Arias (1992) los márgenes sobre los costos diferían del sistema de producción utilizado: sistema extractivo: $92 \%$, caracterizado por escaso uso de insumos, y una mentalidad empresarial de obtener la "máxima extracción" con el mínimo gasto; y en los sistemas PET, el margen era de 51\%. En Antioquia, para el año 2012, de acuerdo con la Cámara de Comercio de Medellín (2012), el sistema especializado de leche tenía altos costos de producción debido a los insumos agropecuarios. Según Guarín (2008), la inflación de los precios de arriendo de las buenas tierras causados por la inseguridad rural, ha hecho que muchos ganaderos busquen tierras más baratas e improductivas. Según la Red Agrinbechmark, (Deblitz (2011b), citado en Flores, 2013) América Latina tiene los costos más bajos, estando los costos más altos en Europa y Estado Unidos.

Respecto a los precios, el gobierno realizó control de precios de forma esporádica en la carne, pero en forma continua en la leche. La finalidad del control de precios era reducir la inflación, y a inicios de los años setenta, el control sobre la venta de carne, como señala García (2006), era para destinar el producto a la exportación. Así mismo, controlaba el precio de la carne en ciertas ciudades, en corte de menor calidad, para favorecer a los consumidores de bajos ingresos. En las épocas de inflación acelerada, el gobierno limitaba las exportaciones de carne para hacer bajar el precio interno. Para la leche, los controles eran más difundidos, en distintas partes de la cadena y según su calidad. El control de precios parece que perjudicó la calidad, al agregársele agua y químicos a la leche para tener más rendimiento. El control de precios posiblemente frenó el desarrollo de la lechería y la lechería especializada.

En los años setenta, según Gómez (1976), el control de precios por parte del Estado no dio resultados, debido a la falta de planeación y la no existencia de un instituto especializado. En los años noventa, en el caso de la carne, el control de precios impedía un precio alto para los animales de calidad, lo cual se unía a los muchos intermediarios y mataderos municipales. En cuanto a la leche, en los años setenta y ochenta, según Vargas (1987), los derivados lácteos no tenían control de precios, y por ello, era una actividad rentable. 
A inicios del siglo XXI, Guarín (2008), establece que el precio de la carne para los sectores populares es alto, lo cual incentiva el comercio tradicional ("para muchos autores, ineficiente, premoderno, antihigiénico") de la carne, que la hace más económica y les permite consumirla.

En lo administrativo y técnico, las empresas u organizaciones ganaderas presentan una escasa aplicación de herramientas administrativas o gerenciales y técnicas. Con base en estudios de Betancur (2015), en el año 2013 tan solo 742 predios fueron certificados con Buenas Prácticas Ganaderas -BPG-, siendo estas empresas excepciones.

Entre los factores externos, están los acuerdos internacionales firmados por el país, dado que, en relación a los acuerdos firmados con la Unión Europea, hay que tener en cuenta que los animales vacunos de estos países reciben subsidios. Así mismo, Quintero (2011), expresa que la cadena láctea se vio afectada con el TLC con Estados Unidos, ya que este país es uno de los mayores productores de carne y leche, aunque había espacio para derivados como el queso; y, en el acuerdo con Canadá, este país es mucho más eficiente en la producción de leche, pero presenta un gran consumo.

Otro factor lo constituyó la inseguridad en todas estas décadas, es así como el sector no creció lo suficiente. Para Vargas (1987), de 1958 a 1985 el hato colombiano creció en 1,81\%. Aunque de acuerdo con FEDEGÁN (2000), la producción de leche creció en los años noventa a pesar de los problemas de inseguridad presentes.

Figura 6. Causas de la baja competitividad del sector lácteo y cárnico en Colombia 1990-2010.

Sector lácteo
Periodos con aftosa. Sin exportación
Falta de calidad en los años 80s
Leche pasteurizada debajo de estándares
internacionales 90 s
Oferta mayor que la demanda 90s
Minifundistas sin transferencia tecnológica
Sector sin asociatividad
Alta informalidad
Gran poder de los industriales en la cadena
Baja densidad por unidad de área en siglo XXI
Escasez de pastos mejorados
Atraso en la tecnología
Inseminación artificial sin estudios genéticos
Deterioro precios del productor
Control de precios
Altos costos de producción
Deficiente manejo gerencial
Cadena primaria sin economías a escala importantes,
sin diferenciación, segmentación de mercados,
marcas, publicidad, bajos inventarios

Falta de integración en la cadena

\section{Sector cárnico}

Declaración de aftosa. Sin exportación

Sistema extensivo. Baja capacidad de carga

Ciclo largo de profucción

Demanda limitada para carne de calidad 90s

Superabundancia de tierras de pastoreo

Los sistemas de recolección, mercados, distribuciór y sacrificio no incentivaban la calidad 90 s

\section{Control de precios 90 s \\ Cadena de intermediarios \\ Sin nuevas tecnologías. Manejo empírico \\ Distribución de la demanda por incremento de precios reales en algunos años}

\section{Baja exportación por falta de calidad}

Ganado cebú de inferior calidad a razas en otros países Sacrificio clandestino

Escasez de pastos mejorados

Praderas de bajo componente alimenticio

Mataderos públicos sin requerimientos exigidos

Animales que llegan tarde al sacrificio

Baja integración de la cadena productiva

Bajas tasas de natalidad y ganancia de peso 
Figura 6. Causas de la baja competitividad del sector lácteo y cárnico en Colombia 1990-2010.

Falta de infraestructura y alta dispersión de los productores origina mercado marginal

Bajo poder de negociación del proveedor

Transporte del animal en pie en lugar de la carne
despostada y empacada
Alta informalidad del sector: incumplimiento
normas sanitarias, comercio tradicional de venta
de carne
Altos costos de producción
Trashumancia
Sistemas de trazabilidad no competitivos
Industria frigorífica sin tecnología moderna
Cercanía de los centros de sacrificio a los centros
de consumo, en lugar de estar cerca de los centros
de producción
Baja diversificación del portafolio exportador
Falta de visión empresarial y asociatividad
Falta de implementación de normas internaiconales
HACCP, BPG, ISO-9001

Fuente: Elaboración propia con base en: FEDEGÁN (2000), Jaramillo y Areiza (2013), Giraldo (2007), Arbeláez (2009), Cámara de comercio de Medellín (2012), Observatorio Agrocadenas (2006), Espinal, Martínez y Acevedo (2005), Cubillos (2015, citado en Mendoza y Pérez, 2016), Calderón y Motta (2013), Mahecha, Gallego y Peláez (2002), Gil (2008), Gómez y Rueda (2011), Mendoza y Pérez (2016), Pinzón (2011, citado en López, et al., 2012), López, et al., ( 2012), García (2006), Botero (2010), Bohórquez, Buitrago, Joya, Montaña, Rivera, (2012), Uribe (1989), Aguilera (2013), FAO y FEPALE (2012), Gamarra (2004), Montes y Candelo (1980).

Al comparar las causas de la no competitividad del sector ganadero colombiano, se observa que muchas se mantienen, mostrando una problemática estructural del sector. Velázquez (1938) había anotado varios de ellos en la década de 1930. En los años sesenta e inicios de los setenta, Cruz et al, (1972), estableció, en gran parte, como limitantes los mismos factores que están en la figura 8.

\subsubsection{Indicadores de productividad del sector ganadero colombiano. Comparativo con otros países.}

La baja competitividad del sector ganadero colombiano se evidencia en los datos que se presentan en las figuras 10 y 11, en donde todos los resultados de los indicadores del país muestran cifras inferiores respecto a los países que están en la vanguardia a nivel mundial o de los países latinoamericanos más destacados en este sector, lo cual indica un rezago del sector desde principios del siglo XX.

En los años setenta, la tasa de extracción era de 3,8\%, y en la década del 2000, de 14\%, indicando una mejoría, pero al compararse con los países de referencia, muestra una baja competitividad, estando siete puntos por debajo de América Latina, la cual presenta una tasa de extracción promedio del 21\% y Argentina, de 25\%; los registros de los otros países líderes en el mercado mundial son bastantes distantes.

Al nivel mundial, el mercado de carnes, de acuerdo con Errecart (2015), presentaba las siguientes cifras: en el año 2013 Estados Unidos tenía el 20\% de la producción mundial; Brasil, el 16\%; la Unión Europea (28 países), un 13\%; China con un 10\%; 
India, un 6\%; Argentina, un 5\%. Los países líderes en el sector cárnico, llevan a cabo controles de calidad y presentan procedimientos para la certificación para la producción de "carne natural" o "carne ecológica". También existen estándares públicos y privados, que, en Estados Unidos evalúan el rendimiento de la canal y la palatabilidad de la carne magra. En este mismo año, Colombia ocupaba el puesto 13, por encima de países como Paraguay y Uruguay. Australia, con un inventario ganadero de 27 millones, contra 23 millones que tenía Colombia, producía 1.188\% más que Colombia en cuanto a carne de res. Rusia, por su parte con un inventario superior en un $8 \%$ al de Colombia producía 155\% más de carne, lo que denota las altas diferencias en competitividad y productividad entre estos países y Colombia.

Respecto al consumo per cápita de carne en Colombia, disminuyó desde los años cincuenta (21 kg/hab de 1953 a 1962, a 17,3 kg/hab en el periodo de 1994 a 2003), motivado por el aumento de los precios reales de la carne y la presencia de productos sustitutos como el pollo y el cerdo (Martínez y Acevedo, 2004, citado en Espinal, et al., (2005). Según la FAO (2002, citado en Aguilera 2006), en Colombia el consumo de carne en la década del 2000, fue de 15,5 kg/hab/año; en el 2012, el DANE (citado en Escobar y Rojo, 2014) mostró una cifra de 20,76 kg/hab/año, mientras que el consumo era de 43,3 kg/hab al año en Estados Unidos y el de la Unión Europea, de 18,9 kg/hab/año, según información de la FAO (2002, citado en Aguilera, 2006).

En el sector lácteo, las cifras tampoco son positivas al compararse con otros países. Bohórquez, et al., (2012), señalan que al final de la primera década del siglo XXI, Colombia ocupa el cuarto lugar como productor de leche en América latina, después de Brasil, México y Argentina. El país con mayor rendimiento en el 2010 fue Israel, gracias al esfuerzo de las instituciones responsables del sector y la adopción permanente de tecnologías innovadoras. De Latinoamérica el primer país fue México en el sexto lugar a nivel mundial, seguido por Argentina. Colombia se ubicó en el puesto 15, después de Chile y Uruguay (Cámara de Comercio de Medellín). Para Quintero (2011), Argentina y Uruguay han logrado alto nivel de productividad y acceso a materias primas de bajo costo. 


\section{Cuadro 2. \\ Indicadores de productividad sector cárnico.}

\begin{tabular}{|c|c|c|c|}
\hline Periodo & Indicadores & Colombia & Otros países \\
\hline $\begin{array}{l}1920 s \\
1920 s \\
1930 s \\
1998 \\
1999 \\
1973-1977\end{array}$ & $\begin{array}{l}\text { Res kilo } \\
\text { Precio kilo } \\
\text { Tiempo para que un animal esté "gordo" } \\
\text { Indicador de sacrificio } \\
\text { Indicador de sacrificio } \\
\text { Tasa de extracción }\end{array}$ & $\begin{array}{l}180 \text { kilos carne } \\
\$ 0,75 \\
\text { Ocho meses } \\
13 \% \\
\text { Entre } 5 \% \text { y } 7 \% \\
3,8 \%\end{array}$ & $\begin{array}{l}\text { Argentina: } 325 \text { kilos carne } \\
\$ 0,09 \\
\text { Argentina: cuatro meses }\end{array}$ \\
\hline 2003 & Tasa de extracción & $197 \mathrm{Kg} / \mathrm{an}$ & $\begin{array}{l}\text { América: } 21 \% \\
\text { Unión Europea: } 35 \% \\
\text { Estados Unidos: } 38 \% \\
\text { Australia: } 31 \% \\
\text { Rusia: } 46 \% \\
\text { Nueva Zelanda: } 41 \% \\
\text { Brasil: } 19 \% \\
\text { Argentina: } 25 \% \\
\text { Promedio mundial: } 204 \mathrm{Kg} / \mathrm{an} \\
\text { Canadá: } 336 \mathrm{Kg} / \mathrm{an} \\
\text { Estados Unidos: } 332 \mathrm{Kg} / \mathrm{an} \\
\text { Argentina: } 222 \mathrm{Kg} / \mathrm{an} \\
\text { Venezuela: } 215 \mathrm{Kg} / \mathrm{an}\end{array}$ \\
\hline 2004 & $\begin{array}{l}\text { Nivel de producción de carne en } \\
\text { función de nivel de inventario }\end{array}$ & $3.2 \%$ & $\begin{array}{l}\text { Estados Unidos: } 11,9 \% \\
\text { Canadá: } 10,2 \% \\
\text { Alemania: } 9,4 \% \\
\text { Francia: } 8,1 \% \\
\text { Rusia: } 7,8 \% \\
\text { Australia: } 7,4 \% \\
\text { Argentina: } 6,0 \%\end{array}$ \\
\hline 2005 & $\begin{array}{l}\text { Peso antes del sacrificio } \\
\text { Ganancia por peso }\end{array}$ & $\begin{array}{l}419 \mathrm{Kg} / \mathrm{cabeza} \\
350 \mathrm{gr} / \text { día }\end{array}$ & $\begin{array}{r}\text { Argentina: } 509 \mathrm{Kg} / \mathrm{an} \\
550 \mathrm{gr} / \text { día }\end{array}$ \\
\hline 2008 & Productividad animal & $39 \mathrm{Kg} /$ animal/año & $\begin{array}{l}\text { Argentina: } 58 \mathrm{Kg} / \text { carne/año } \\
\text { Australia: } 75 \mathrm{Kg} / \text { animal/año } \\
\text { Estados Unidos: } 125 \mathrm{Kg} / \text { animal }\end{array}$ \\
\hline \multirow[t]{2}{*}{ 2000-2009 } & $\begin{array}{l}\text { Peso en canal } \\
\text { Peso animal enviado a la "faena" } \\
\text { Edad al sacrificio }\end{array}$ & $\begin{array}{l}350 \mathrm{gr} / \mathrm{d} \\
48 \text { meses }\end{array}$ & $\begin{array}{l}\text { Argentina y Uruguay: } 500 \text { gr/d } \\
\text { Argentina: } 350-480 \mathrm{Kg} \\
\text { Argentina y Uruguay: }<36 \text { meses }\end{array}$ \\
\hline & Capacidad de carga & $\begin{array}{l}0,6 \text { unidades de } \\
\text { ganado por } \\
\text { héctarea }\end{array}$ & $\begin{array}{l}\text { Argentina y Uruguay: oscila entre } \\
0,8 \text { y } 1,2 \text { unidades de ganado } \\
\text { por hectárea }\end{array}$ \\
\hline \multirow[t]{2}{*}{2013} & $\begin{array}{l}\text { Tasa de extracción } \\
\text { Peso en canal Kg } \\
\text { Rendimiento en canal } \\
\text { Peso en Kg sacrificio machos } \\
\text { Ganancia de peso diario (gr/animal/día) } \\
\text { Edad de sacrificio en días }\end{array}$ & $\begin{array}{l}20,50 \% \\
205,00 \\
52 \% \\
450,00 \\
325\end{array}$ & $\begin{array}{l}\text { Estados Unidos: } 34 \% \\
330,00 \\
62 \% \\
672,00 \\
1.400\end{array}$ \\
\hline & & 1.170 & 480 \\
\hline 2013 & Sistema de producción dominante & $\begin{array}{l}\text { Pastoril extensivo/ } \\
\text { semi intensivo }\end{array}$ & Confinamiento \\
\hline
\end{tabular}

Fuente: Elaboración propia con base en Posada (2006), Mahecha, et al., (2002), Espinal et al., (2005), Llorente (1986), Agribenchmark, 2013, citado en Espinosa (2014), Gómez y Rueda (2011), Barrera (2010), Santarcángelo y Fal (2009), Velázquez (1938). 


\section{Indicadores de productividad del sector lácteo.}

\begin{tabular}{|c|c|c|c|}
\hline Periodo & Indicadores & Colombia & Otros países \\
\hline $\begin{array}{l}\text { Principios } \\
\text { siglo XX }\end{array}$ & Producción por vaca/día & 2 lts & \\
\hline 1950s & Producción por vaca/día & 4-5 lts/día & Estados Unidos: 7,5 lts/día \\
\hline \multirow[t]{4}{*}{$1960 \mathrm{~s}$} & $\begin{array}{l}\text { Producción por vaca/día para } \\
\text { ganado especializado }\end{array}$ & 6-9 lts/día & \\
\hline & Ganado especializado con suplemento & 12-17 lts/día & \\
\hline & Ganado doble propósito & 2,5-5 lts/día & \\
\hline & Rendimiento promedio & $\begin{array}{l}2,7 \text { lts/día o } 2,9 \\
\text { lts/día }\end{array}$ & $\begin{array}{l}\text { Estados Unidos: } 17 \text { lts/día } \\
\text { Argentina: } 7,2 \text { lts } \\
\text { México: } 4 \text { lts. } \\
\text { Brasil: } 2 \text { lts. } \\
\text { India: } 1,9 \text { lts. }\end{array}$ \\
\hline
\end{tabular}

\begin{tabular}{|c|c|c|c|}
\hline \multirow[t]{6}{*}{$1980 s-1990 s$} & $\begin{array}{l}\text { Rendimiento ganado especializado } \\
\text { sin suplementación }\end{array}$ & 6-9 lts/día & \\
\hline & Rendimiento ganado con suplementación & 12-17 lts/día & \\
\hline & Rendimiento promedio & 2,5 lts/día & Estados Unidos: 17 lts/día \\
\hline & & & Canadá: 14,5 lts \\
\hline & & & Argentina: 7,2 lts \\
\hline & & & México: 4,2 lts \\
\hline \multirow[t]{4}{*}{$1995-2001$} & Relación pastura/cabezas de ganado & Capacidad de carga: & Brasil: 1 UGG por ha \\
\hline & & 0.65 Unidad de Gran & Argentina: $>0,5$ \\
\hline & & Ganado (UGG) por ha & Uruguay: entre 0,8 y 1,2 \\
\hline & & Región Caribe: 1 UGG & \\
\hline \multirow[t]{4}{*}{$1992-2003$} & Incremento de la productividad & $\begin{array}{l}\text { Sistema doble } \\
\text { propósito: } 44 \%\end{array}$ & \\
\hline & Disminución costo de producción & $\begin{array}{l}\text { Lechería } \\
\text { especializada: } 14 \%\end{array}$ & \\
\hline & & $\begin{array}{l}\text { Sistema doble } \\
\text { propósito: } 16 \%\end{array}$ & \\
\hline & & $\begin{array}{l}\text { Lechería } \\
\text { especializada: 10\% }\end{array}$ & \\
\hline \multirow[t]{6}{*}{2010} & Producción anual & 1.415 lts promedio/ & Israel: 10.337 lts/animal/año \\
\hline & & animal/año & Estados Unidos: $9.525 \mathrm{lts}$ \\
\hline & & & Dinamarca: 8.640 lts \\
\hline & & & Canadá: 8.802 \\
\hline & & & México: 4.541 lts \\
\hline & & & Argentina: 4.496 lts \\
\hline \multirow[t]{2}{*}{2012} & Rendimiento promedio nacional & $\begin{array}{l}\text { Colombia: } 4,5 \text { litros/ } \\
\text { vaca/día }\end{array}$ & \\
\hline & & $\begin{array}{l}\text { Departamento del } \\
\text { Atlántico: } 3.9\end{array}$ & \\
\hline
\end{tabular}

Fuente: Elaboración propia con base en Eder, citado en Kalmanovitz y Encizo (2005), Gómez (1976), Mejía (2012), Gómez y Rueda (2011), Hollman, et al., 2004). 


\section{CONCLUSIONES}

El recorrido de la actividad ganadera colombiana ha sido largo, a pasos y cambios moderados, con tropiezos u obstáculos desde lo interno del sector y sus organizaciones como del contexto externo, aunque también se han presentado oportunidades para el sector.

En su historiografía, los autores desarrollan tres vías para analizar la expansión de la hacienda ganadera: quienes observan la actividad como un mecanismo para la acumulación de tierras, obtener poder y prestigio social, logrando una rentabilidad por medios diferentes; los que consideran que el ganadero siempre ha aspirado a la obtención de ingresos por medio de esta actividad económica así como el prestigio, incluido el político, y el poder; y, aquellos autores que observan la racionalidad económica del ganadero y lo consideran un empresario, que al analizar las circunstancias del entorno decide implementar un sistema que no es competitivo en términos internacionales, pero puede operar en el mercado interno.

El país, dadas las condiciones políticas, sociales y geográficas, no pudo iniciar con fuerza la actividad ganadera, inclusive no presentaba algunas ventajas comparativas presentes en otros países para el desarrollo del sector, incrementándose los costos de la operación. Los cambios se fueron presentando en las primeras décadas del siglo XX en forma lenta y dispersa. En la segunda mitad de siglo XX se dieron aspectos que hicieron avanzar al sector ganadero, como fue la eliminación del levante.

En los últimos años se evidencia una ganadería que abastece el mercado interno, hay un crecimiento en el área de pastos; un cruce genético acorde con el clima, la consolidación de las subastas ganaderas, presencia de frigoríficos, industria láctea, entre otros aspectos. Dos ventajas comparativas han continuado en el país: una producción forrajera permanente y mano de obra barata, pero, al mirarse los resultados del sector denotan no haber sido aprovechadas.

La productividad y la calidad, continúan estando por debajo de los estándares mundiales. Colombia, a pesar de pasar por tantas décadas, no ha logrado llegar a estos indicadores, tanto así que parte de sus exportaciones en el siglo XX se han dirigido a países cercanos o a mercados internacionales con requerimientos de calidad que no son exigentes y no corresponden propiamente a mercados exclusivos.

Las razones para esta situación se basan primordialmente en la existencia de una ganadería extensiva, el número de intermediarios, la falta de integración de la cadena, aunque ésta ha mejorado; mala calidad de pastos; administración deficiente; cruces genéticos impropios; problemas sanitarios; ciclo ganadero largo; problemas de precios, inseguridad; reformas fiscales; entre otros. La permanencia de este sistema con sus motivos económicos, sociales y culturales, corresponde a un círculo que ha permanecido más de 150 años.

En la ganadería cárnica, indicadores como la tasa de extracción, la productividad animal o el peso antes del sacrificio; y en el sector lácteo, los indicadores de rendimiento promedio o producción anual, están muy por debajo de los resultados de los países netamente exportadores. En el caso del sector lácteo hay desarrollos importantes en la industria. 


\section{REFERENCIAS BIBLIOGRAFICAS}

Aguilera, M. (2006). El Canal Del Dique y su Subregión, una Economía Basada en la Riqueza Hídrica. Banco de la República, 72. Recuperado de http://www. banrep.gov.co/es/contenidos/publicacion/canal-del-dique-y-su-subregi-nuna-econom-basada-riqueza-h-drica

Aguilera, M. (2013). Montes de María: Una subregión de economía campesina y empresarial. Banco de la República, 195. Recuperado de http://www. banrep.gov.co/sites/default/files/publicaciones/archivos/dtser_195.pdf

Álvarez, J. (2012). Holstein: la nodriza de los antioqueños. Historia Crítica, 48, 83109. Recuperado de http://www.scielo.org.co/pdf/rhc/n48/n48a05.pdf

Arbeláez, L. (2009). Estructura de costos en la cadena de valor del productor de leche. Medellín, Colombia: Universidad EAFIT.

Arias, J. (1992). La ganadería en la formación social colombiana. Bogotá, Colombia: Ministerio de Agricultura.

Arias, J. (2004). Ganadería, Paisaje, Territorio y Región. Una Historia Ecológica y Social de la Orinoquia Colombiana. Documento inédito. Instituto de investigación de recursos biológicos Alexander von Humboldt.

Barrera, H. (2010). La función de la demanda observada de carnes en Colombia (2000-2007): Análisis comparativo de varios modelos econométricos. Rev. maest.derecho.econ, 6 (6), 179-220. Recuperado de http://revistas.javeriana. edu.co/index.php/revmaescom/article/view/7171/5699

Barrios, D., y Olivera, M. (2013). Análisis de la competitividad del sector lechero: caso aplicado al norte de Antioquia, Colombia. INNOVAR. Revista de Ciencias Administrativas y Sociales, 23 (48), pp. 33-41. Recuperado de http://www.redalyc.org/articulo.oa?id=81828690004

Bejarano, J. (1987). El Despegue Cafetero (1900-1928). En Ocampo, J. (Ed.), Historia económica de Colombia. Bogotá, Colombia: Fedesarrollo - Siglo XXI Editores.

Bell, P. (1921). Colombia, Manual comercial e industrial. Washington, D.C, Estados Unidos: Imprenta del Gobierno.

Betancur, A. (2015). Implementación de las buenas prácticas ganaderas en la hacienda La Ponderosa, ubicada en el municipio de San Pedro de Urabá (Antioquia) (trabajo de posgrado), Corporación Universitaria Lasallista, Caldas.

Bohórquez, N., Buitrago, A., Joya, M., Montaña, X., y Rivera, H. (2012). Análisis estructural de sectores estratégicos: sector productos lácteo. Universidad del Rosario, Documento de Investigación, 135.

Bolívar, I. (2008). Discursos estatales y geografía de consumo de carne de res en Colombia. Bogotá, Colombia: Pontificia Universidad Javeriana. 
Bonet, J. (1998). El Ganado Costeño en la Feria de Medellín, 1950-1997. Banco de la República, 5.

Bossa, D. (1967). Cartagena independiente, tradición y desarrollo. Bogotá, Colombia: Ediciones Tercer Mundo.

Botero, A. (2010). Trashumancia y Dinámicas Socioculturales - Sabanas de Magangué y planicie inundable de Santa Cruz de Mompox, región Caribe colombiana (trabajo de posgrado). Pontificia Universidad Javeriana, Bogotá.

Brew, R. (2000). El desarrollo económico de Antioquia desde la independencia hasta 1920. Medellín, Colombia: Universidad de Antioquia.

Bowser, F. (1969). Prerrequisitos y potencial para la exportación de carne en Colombia en la década de 1970. Misión de la Universidad de Nebraska en Colombia, Departamento de Economía Agrícola, ICA. Recuperado de http:// ufdc.ufl.edu/UF00054294/00001/1j

Burgos, R. (2000). El general Burgos. Segunda Edición. Bogotá, Colombia: Gobernación de Bolívar, Instituto Internacional de Estudios del Caribe.

Calderón, C., y Motta, V. (2013). Inspección, vigilancia y control de las plantas de beneficio animal y su importancia en la salud pública colombiana (Trabajo de posgrado). Universidad Militar Nueva Granada, Bogotá.

Cámara de Comercio de Medellín (2012). Cadena láctea en Antioquia. Informes estudios económicos. Recuperado de http://www.camaramedellin.com. co/site/Portals/0/Documentos/2017/Publicaciones\%20regionales/5\%20 Lacteos_Oct19.pdf

Carro, R., y González, D. (2012). Competitividad y productividad. Universidad Nacional de Mar del Plata. Recuperado de http://nulan.mdp.edu. ar/1607/1/02_productividad_competitividad.pdf

Cruz, J., Peñuela, J., Gómez, F., y Cedeño, G. (1972). Bases para el desarrollo de la ganadería bovina en Colombia. Tomo I. Bogotá, Colombia: Instituto Colombiano Agropecuario.

Cuenca, N., Chavarro, F., y Díaz, O. (2008). El Sector de Ganadería Bovina en Colombia. Aplicación de Modelos de Series de Tiempo al Inventario Ganadero. Revista Facultad de Ciencias Económicas, 16, 165-177. Recuperado de http://www.scielo.org.co/pdf/rfce/v16n1/v16n1a12.pdf

Currie, L. (1962). La industria ganadera y la nación. El desarrollo de la ganadería doble propósito. Bogotá, Colombia: Banco Colombia, Almacenes de Depósito Mercantil, S. A.

Departamento de Investigaciones Económicas de la Caja de Crédito Agrario (1961). Recomendaciones para la solución de algunos problemas de la ganadería en el departamento de Córdoba. Bogotá, Colombia: Departamento de Investigaciones Económicas de la Caja de Crédito Agrario. 
Departamento Nacional de Planeación (1980). La economía ganadera en Colombia. Revista Planeación y Desarrollo, 91-137.

Errecart, V. (2015). Análisis del mercado mundial de carnes. Recuperado de http:// www.unsam.edu.ar/escuelas/economia/economia_regional/CERE\%20 -\%20Mayo\%20-\%202015.pdf

Escobar, S., y Rojo, A., (2014). El Sacrificio de Ganado en Colombia, una caracterización desde las series de tiempo. EAFIT, Medellín.

Espinal, F., Martínez, H., y Acevedo, J. (2005). La cadena de carne bovina en Colombia. Una mirada global de su estructura y dinámica 1991-2005. Ministerio de Agricultura y Desarrollo Rural. Observatorio Agrocadenas Colombia, 73.

Espinosa, M. (2014). Análisis de la productividad de la ganadería cárnica en Colombia y su participación en el PIB (2003 - 2013) frente al TLC con Estados Unidos (Trabajo de pregrado). Recuperado de https://repository. eafit.edu.co/ bitstream/handle/10784/8319/MariaCamila_EspinosaGarcia _2014.pdf?sequence=2

Fals, O. (1987). Retorno a la tierra. Historia doble de la costa. Tomo IV. Bogotá, Colombia: Carlos Valencia Editores.

Federación Antioqueña de Ganaderos (1980). La ganadería vacuna en Colombia. Medellín, Colombia: FADEGÁN.

Federación de Ganaderos (2000). La ganadería bovina en Colombia 1999-2000. Bogotá, Colombia: FEDEGÁN.

FAO (2012). Situación de la lechería en América Latina y el Caribe en el 2011. Recuperado de http://www.fao.org/fileadmin/templates/est/COMM_ MARKETS_MONITORING/Dairy/Documents/Paper_Lecher\%C3\%ADa_ AmLatina_2011.pdf

Flores, M. (2013). Mercado mundial y cadena de valor de la carne bovina. Documento de trabajo 90, Universidad de la República. Recuperado de http:// cienciassociales.edu.uy/departamentodesociologia/wp-content/uploads/ sites/3/2013/archivos/90.pdf

Gallini, S. (2005). El Atila del Ganges en la ganadería colombiana. Nómadas, 22, 186-197. Recuperado de http://nomadas.ucentral.edu.co/index.php/27medio-ambiente-historia-y-politica-nomadas-22/385-el-atila-del-gangesen-la-ganaderia-colombiana

Gamarra, J. (2004). Eficiencia técnico relativa de la ganadería doble propósito de la costa Caribe. Banco de la República, 53. Recuperado de http://www.banrep. gov.co/docum/Lectura_finanzas/pdf/DTSER-53.pdf 
García, J. (2006). Las Políticas Económicas y el Sector Ganadero en Colombia: 19501977. Banco de la República, 5. Recuperado de http://www.banrep.gov.co/ docum/Lectura_finanzas/pdf/chee_19.pdf

Griful, E., y Canela, M. (2005). Gestión de la calidad. Barcelona, España: Ediciones UPC.

Gómez, A. (1976). La ganadería en América Latina. Colombia. Bogotá, Colombia: Ediciones Tercer Mundo.

Giraldo, J. (2007). Una mirada al uso de la inseminación artificial en bovinos. Revista Lasallista, 4 (1), 51-57. Recuperado de http://www.redalyc.org/ pdf/695/69540108.pdf

Gómez, J., y Rueda, R. (2011). Productividad del Sector Ganadero Bovino en Colombia Durante los Años 2000 a 2009 (Trabajo de pregrado). Recuperado de http:// repository.urosario.edu.co/bitstream/handle/10336/2629/1047396260-2011.pdf

Gil, J. (2008). TLC, globalización y el futuro de la ganadería en Colombia. El CuadernoEscuela de Ciencias Estratégicas, 2 (3), 23-51. Recuperado de https://dialnet. unirioja.es/servlet/articulo?codigo $=2728859$

Guarín, A. (2008). Carne de cuarta para consumidores de cuarta. Revista de Estudios Sociales, 29, 104-119. Recuperado de http://www.scielo.org.co/pdf/res/ n29/n29a07.pdf

Hertford, R. y Nores, G. (1982). Caracterización del sector ganadero de Colombia 1953 a 1975. Cali, Colombia: Centro Internacional de Agricultura Tropical, CIAT.

Hollman, F., Rivas, L., Carulla, J., Rivera, B., Guzmán, S., Martínez, M., Medina, A. y Farrow, A. (2004). Producción de leche y su relación con los mercados. Caso colombiano. CIAT-ILRI.

Horta, R. y Jung, A. (2002). Competitividad e industria manufacturera. Aportes para un marco de análisis. Revista electrónica de la Facultad de Ciencias Económicas de la Universidad Católica, 1 (1), 1-38.

Jaramillo, C., y Caicedo, E. (1996). Caracterización del ciclo ganadero. Departamento Nacional de Planeación.

Jaramillo, A., y Areiza, A. (2013). Análisis del mercado de leche y derivados lácteos en Colombia (2008 - 2012). Superintendencia de Industria y Comercio. Recuperado de http://www.sic.gov.co/recursos_user/documentos/ promocion_competencia/Estudios_Economicos/Estudios_Economicos/ Estudio_Sectorial_Leche1.pdf

Kalmanovitz, S., y Enciso, E. (2005). Aspectos de la agricultura colombiana en el siglo XX. Recuperado de http://avalon.utadeo.edu.co/comunidades/grupos/ salomonk/ensayos/Aspectos $\% 20$ de $\% 20$ la $\% 20$ agricultura $\% 20$ colombiana\%20en\%20el\%20siglo\%20XX.pdf 
Legrand, C. (1988). Colonización y protesta campesina en Colombia, 1850-1950. Bogotá, Colombia: Universidad Nacional.

Llorente, L. (1986). La ganadería bovina en Colombia. Bogotá, Colombia: Editorial Siglo XXI Editores.

Londoño, E. (2013). Estrategia para una empresa del sector ganadero en Colombia: Implementación del sistema de gestión "The Execution Premium". Universidad EAFIT, Medellín.

López, A. (1927). Problemas colombianos. Paris, Francia: Editorial Paris - América.

López, M., Andrade, R., Muñoz, N., y Pulido, M. (2012). Potencial ganadero de Colombia para exportar cortes finos de carne de bovino a la unión europea, Ciencia y agricultura, 9 (2), 57-63. Recuperado de https://dialnet.unirioja. es/descarga/articulo/4986454.pdf

Machado, A. (1989). Las exportaciones de carnes y el Packing Hauses de Coveñas 1918-1938. Corporación Tecnológica de Bolívar, Cartagena.

Mahecha, L., Gallego, L., y Peláez, F. (2002). Situación actual de la ganadería de carne en Colombia y alternativas para impulsar su competitividad y sostenibilidad. Rev Col Cienc Pec, 15 (2). Recuperado de https://dialnet. unirioja.es/descarga/articulo/3242901.pdf

Martínez, A. (2011). Respuestas de los precios del ganado macho de levante en las ciudades de Sincelejo y Montería frente a cambios en las variables externas en el período 2000-2009. Desarrollo regional y competitividad, 5-18. Recuperado de https://www.cccartagena.org.co/sites/default/files/ revistas_pdf/articulo_1_3.pdf

Medina, L., Sejín, C., Saa, R., Bustamante D. y Ochoa, R. (1984). La ganadería bovina en Córdoba. Montería, Colombia:Gobernación de Córdoba, Ministeriode Agricultura.

Meisel (2009). ¿Por qué perdió la costa Caribe el siglo XX? En Meisel, A. (Ed.), ¿Por qué perdió la costa Caribe el siglo XX? Y otros ensayos (169-202). Cartagena, Colombia: Banco de la República.

Meisel, A. y Viloria, J. (1999). Los alemanes en el Caribe colombiano. El caso de Adolfo Held. Banco de la República, 1.

Mejía, E. (2003). Ciro Molina Garcés y Carlos Durán Castro: gestores y científicos en el desarrollo agropecuario del Valle del Cauca. En Dávila, C. (Comp.), Empresas y Empresarios en la historia de Colombia. Siglos XIX-XX (1.1891.214). Bogotá, Colombia, Ediciones Uniandes, Norma.

Mejía, F. (2012). Prospectiva de la cadena láctea del Departamento de Nariño al horizonte del año 2020. Tendencias, 13(1), 36-54. Recuperado de http:// revistas.udenar.edu.co/index.php/rtend/article/view/514/540 
Mendoza, W. y Pérez, Y. (2016). Estudio del comportamiento de la producción de carne bovina en algunos países de américa latina mediante el uso de modelos de datos panel para el periodo de 1995-2014. Fundación Universitaria Los Libertadores, Bogotá.

Ministerio de Agricultura y Desarrollo Rural (2003). Anuario 2003. Observatorio de Agrocadenas. Primera Edición. Bogotá, Colombia: Ministerio de Agricultura y Desarrollo Rural.

Montes, G., y Candelo, R. (1980). La economía ganadera en Colombia. Bogotá, Colombia: DNP.

Negrete, R. (2009). Una biografía parcial de Manuel Burgos y sus actividades empresariales en la Hacienda Berastegui. Universidad Santiago de Cali. Recuperado de: http://gideei-universidadsantiagodecali.blogspot.com. co/2010/02/memorando-gideei-04-una-biografia.html

Observatorio Agrocadenas (2006). Segundo informe de coyuntura de leche 2006. Recuperado de http://www.redlactea.org/wp-content/uploads/ documentos/Infcoy206.pdf

Ocampo, G. (2007). La instauración de la ganadería en el valle del Sinú: la hacienda Marta Magdalena, 1881-1956. Primera edición. Medellín, Colombia:

Editorial Universidad de Antioquia.

Pérez, G. (2004). Los ciclos ganaderos en Colombia, 1951 - 2001. Cartagena: Banco de la República, 46. Recuperado de http://www.banrep.gov.co/docum/ Lectura_finanzas/pdf/DTSER-46.pdf

Pérez, L. (2015). El cebuismo y la transformación agropecuaria del nororiente de Colombia durante el siglo XX. Ensayo de Economía, 46, 157-177. Recuperado de https://revistas.unal.edu.co/index.php/ede/article/download/53633/53079

Pertuz, A. (2008). Historia empresarial de Sincelejo, años 1936-1950. Búsqueda, 9, 44-64.

Posada, E. (1994). Historia económica del Caribe colombiano Progreso y estancamiento 1850 - 1950. Bogotá, Colombia: Ediciones Uninorte, ECOE Ediciones, CERES.

Posada, E. (2003). Empresarios y ganaderos en la costa Atlántica (1850-1950). Bogotá, Colombia: Ediciones Uniandes- Editorial Norma.

Posada, E. (2006). El Caribe colombiano. Una historia regional (1870-1950). Bogotá, Colombia: Banco de la República, El Áncora Editores.

Quintero, E. (2011). Evolución y desarrollo del sector lácteo en Colombia desde la perspectiva del sector primario (producción). Corporación Universitaria Lasallista, Bogotá. 
Reyes, A. (2015). Destinadas a un destino. Los inicios de las exportaciones argentinas de carnes frigoríficas, 1883-1913. E.I.A.L, 26 (1), 7-30. Recuperado de http:// eial.tau.ac.il/index.php/eial/article/download/1315/1358

Reyes, A. (1978). Latifundio y poder político. La hacienda ganadera en Sucre. Bogotá, Colombia: Cinep.

Ripoll, M. (1997). El Central Colombia. Inicios de industrialización en el Caribe colombiano. Boletín cultural y bibliográfico, 34 (45).

Ripoll, M. (1999). La actividad empresarial de Diego Martínez Camargo, 1890-1937. Banco de la República, 2.

Rivas, L. (1981). Aspectos económicos del sector ganadero en Colombia. CIAT.

Rivas, L., y Cordeu, J. (1983). Potencial de producción de carne vacuna en América Latina: estudio de casos. Cali, Colombia: Centro Internacional de Agricultura Tropical.

Santana, A. (2014). Costos modales en ganadería de leche. Trópico alto de Colombia: Ventana a la competitividad ganadera. Bogotá: FEDEGÁN - SENA.

Santarcángelo, J.; Fal, J. (2009). Producción y rentabilidad en la ganadería argentina. 1880-2006. Mundo agrario, 10 (19). Recuperado de http://www. mundoagrario.unlp.edu.ar/article/view/v10n19a02/609

Sourdís, A. (2008). Ganadería en Colombia: cinco siglos construyendo país. Bogotá, Colombia: FEDEGÁN

Ubfal, D. (2004). El concepto de competitividad. Medición y aplicación al caso argentino. Instituto investigaciones económicas, 15. Recuperado de http:// bibliotecadigital.econ.uba.ar/download/docin/docin_cenes_015

Uribe, L. (2011). Las exportaciones de ganado en la "Hacienda La Morela". Municipio de Puerto Berrío (Antioquia - Colombia), 1965-1968. HISTORelo, 5, 73 112. Recuperado de https://revistas.unal.edu.co/index.php/historelo/ article/view/19026/pdf_47

Uribe, C. (1989). El sector pecuario colombiano: evolución, perspectivas y potencial exportador. Revista Nacional de Agricultura, 888, 103-143.

Van Ausdal, S. (2009). Potreros, ganancia y poder. Una historia ambiental de la ganadería en Colombia. 1850-1950. Historia Crítica, 126-149. Recuperado de http://www.redalyc.org/articulo.oa?id=81112369008

Vargas, A. (1987). La ganadería en Colombia. Bogotá, Colombia: Banco de la República.

Velázquez, J. (1938). El problema ganadero en Colombia. Rev. Med. Vet. Zoot., 8, 20-30. Recuperado de https://revistas.unal.edu.co/index.php/remevez/ article/view/53423/52919 
Viloria, J. (2005). La ganadería bovina en las llanuras del Caribe colombiano. En Gerson, J. (Ed.), Microeconomía de la ganadería en Colombia (74-137). Cartagena, Colombia: Banco de la República.

Viloria, J. (2004). La economía ganadera en el departamento de Córdoba. Banco de la República, 43. Recuperado de http://www.banrep.gov.co/docum/ Lectura_finanzas/pdf/DTSER-43.pdf

Viloria, J. (2001). Ganaderos y Comerciantes en Sincelejo, 1880-1920. Banco de la República, 8. Recuperado de: http://www.banrep.gov.co/es/ganaderos$\mathrm{y}$-comerciantes-sincelejo-1880-1920 